\title{
JUEZ ESPAÑOL, DERECHO EUROPEO Y MAYOR PROTECCIÓN DE LOS DERECHOS FUNDAMENTALES
}

ÁNGEL RODRÍGUEZ-VERGARA DÍAZ

Profesor Titular de Derecho Constitucional Universidad de Málaga 


\section{SUMARIO}

I. Introducción; II. Derecho Europeo y Derechos Fundamentales; A) La Convención Europea de Derechos Humanos; B) El Derecho Comunitario EurOpeo; III. DERECHO EUROPEO Y MAYOR PROTECCIÓN DE LOS DERECHOS FUNDAMENTALES; A) Convención Europea de Derechos Humanos y mayor protección de los derechos fundamentales; B) Derecho comunitario europeo $y$ mayor protección de los derechos fundamentales; IV. Conclusiones. 


\title{
JUEZ ESPAÑOL, DERECHO EUROPEO Y MAYOR PROTECCIÓN DE LOS DERECHOS FUNDAMENTALES*
}

POR

\author{
ÁNGEL RODRÍGUEZ-VERGARA DÍAZ** \\ Profesor Titular de Derecho Constitucional \\ Universidad de Málaga
}

\section{INTRODUCCIÓN}

El objeto de esta ponencia es explorar la posibilidad de aplicar el criterio de mayor protección a las relaciones entre las normas sobre derechos fundamentales del ordenamiento español y las de los ordenamientos europeos.

- Este texto se corresponde con la conferencia pronunciada en Ávila el 14 de julio de 1998, en el curso de verano de la Universidad Nacional de Educación a tancia "El Poder Judicial a debate», dirigido por el prof. Dr. Antonio Torres del Moral. La transcripción del texto ha sido objeto de las oportunas correcciones, pero se ha preferido, en la medida de lo posible, respetar su formato original. Ello explica la ausencia de aparato doctrinal, que se ha reducido a las citas imprescindibles en el texto.

"* angel.rodriguez@uma.es 
En líneas generales, podemos caracterizar el criterio de mayor protección como la posibilidad que debe tener el juez de seleccionar de entre las normas aplicables aquella que dispense un estándar mayor de protección a los derechos fundamentales concernidos en el caso. Se trataría, por lo tanto, de un criterio jurisprudencial de selección de la norma aplicable, lo que le diferenciaría, por ejemplo, del principio de favor libertatis, que es un principio de interpretación de las normas. Su posibilidad de aplicación se reduciria, por lo tanto, a aquellos casos en los que existen varias normas, dotadas todas ellas de los atributos de vigencia y validez necesarios para su aplicación, situación que, si aceptamos como válidos los postulados de plenitud y autointegración del ordenamiento jurídico, sólo podría darse en presencia de varios ordenamientos, todos ellos con vocación normadora sobre un caso concreto. Todavía en estas circunstancias sería posible acudir a otros criterios distintos del que aquí se estudia para seleccionar el ordenamiento aplicable, lo que reduciría aún más la posibilidad de aplicación del criterio de mayor protección a los casos en los que esos criterios no existieran o que, existiendo, no dieran una respuesta clara y determinante sobre qué norma (qué norma de qué ordenamiento) aplicar.

Aunque la idea de mayor protección está inspirada en la práctica de Estados Unidos, y por lo tanto de un Estado compuesto en el que el ordenamiento federal convive con los ordenamientos de los Estados federados, un lugar natural para ensayar su aplicación lo constituye el estado actual de la integración jurídica europea, en el que varios ordenamientos conviven sin fronteras precisas que delimiten sus respectivos campos de aplicación. Este es, en efecto, el modo en el que puede caracterizarse la relación actual entre los diversos ordenamientos cuyas normas protegen los derechos fundamentales en Europa.

Descrita en términos sencillos, puede pues decirse que la cuestión sobre la que esta ponencia pretende esbozar algunas propuestas es la que se presenta al juez español que se enfrenta a un problema de derechos fundamentales constitucionales en el que está también implicado el derecho Europeo. En ella se sostendrá la hipótesis de que, en estas circunstancias, el juez español debe tratar de otorgar a los derechos fundamentales la mayor protección que le dispense, en cada caso, cualquiera de los ordenamientos aplicables. Para conseguir este resultado, se analizará a continuación cómo puede el juez articular la aplicación de varios ordenamientos -e interpretar las diversas normas que pueblan cada uno de ellos- en un caso concreto en el que los derechos fundamentales protegidos constitucionalmente estén concernidos. 
En primer lugar, analizaremos de forma muy breve cuáles son los ordenamientos europeos a los que nos estamos refiriendo, para estudiar, después, de qué modo podría aplicarse el criterio de mayor protección en cada uno de ellos por parte de un juez español.

\section{DERECHO EUROPEO Y DERECHOS FUNDAMENTALES}

Cuando hablamos del "derecho europeo" estamos haciendo referencia, en realidad, a dos ordenamientos diferentes, si bien en estrecha relación: el derecho de la Convención Europea de Derechos Humanos y el ordenamiento comunitario. Ambos protegen, cada uno con sus características propias, derechos fundamentales reconocidos por la CE.

En cuanto al modo constitucionalmente dispuesto para su aplicación en España es preciso distinguir entre, en primer lugar, la recepción interna de todos los tratados internacionales, entre ellos los que protejan derechos fundamentales. Según lo estipulado por el art. 96 $\mathrm{CE}$, estas normas forman parte del ordenamiento interno. En su virtud, una vez válidamente celebrados y publicados oficialmente en España, pueden ser alegados como fuente de derecho ante los tribunales españoles, con las particularidades que se establezcan en cada caso. Este precepto es de aplicación tanto a la CEDH como a los tratados que constituyen el derecho comunitario originario.

En segundo lugar, la recepción interna de los tratados sobre derechos fundamentales. Además de la recepción general anterior, la CE contiene en su art. 10. 2 una norma específica para las normas internacionales sobre derechos humanos. Según este artículo,

"Las normas relativas a los derechos fundamentales y a las libertades que la Constitución reconoce se interpretarán de acuerdo con la Declaración Universal de Derechos Humanos y los tratados y acuerdos internacionales sobre las mismas materias ratificados por España".

En virtud de esta disposición constitucional, la Declaración Universal de Derechos Humanos y los tratados internacionales sobre derechos fundamentales se erigen como criterios de interpretación de las normas internas sobre la materia, incluso cuando la norma a interpretar es la propia norma constitucional.

En tercer lugar, la recepción del derecho comunitario europeo. EI art. 93 CE posibilita que se deleguen en las instituciones comunitarias competencias derivadas de la Constitución. Gracias a esta posibilidad las normas comunitarias de derecho derivado se aplican en nuestros 
país, como se sabe, siguiendo los principios establecidos por el TJCE, particularmente los de primacía y efecto directo, tal como han sido definidos por la jurisprudencia comunitaria, desde las SSTJCE Costa $v$ ENEL, de 15 de julio de 1964, y Siementhal, de 9 de marzo de 1978.

Tanto la CEDH como el derecho comunitario (originario y derivado) contienen normas que protegen derechos fundamentales reconocidos constitucionalmente.

\section{A) La Convención Europea de Derecho Humanos'}

El catálogo de derechos protegidos por la Convención fue, inicialmente, muy reducido: sólo los derechos fundamentales que se entendían indispensables en cualquier Estado democrático fueron incluidos en un primer momento. No parece haber disputa doctrinal alguna acerca del hecho de que fuera precisamente ésta la intención inicial de los redactores de la Convención: estàblecer el estándar mínimo de derechos fundamentales que debía ser respetado por todos los Estados europeos que aspiraran a ingresar en el Consejo de Europa. De este modo, se recogieron los derechos a la vida, a no ser sometido a tortura o tratos inhumanos o degradantes y a no ser sometido a esclavitud; el derecho a la libertad y seguridad y las garantías que deben rodear su privación; el derecho a un juicio justo con todas sus garantías; el derecho a no ser condenado por actos que no hayan sido tipificados previamente como delito; los derechos a la intimidad, libertad de pensamiento, de expresión y manifestación y el derecho a contraer matrimonio. Posteriormente, sin embargo, se ha ido ampliado el catálogo de derechos protegidos mediante la aprobación de diversos protocolos adicionales que han venido añadiéndose al texto original desde poco tiempo después de su aprobación hasta el momento presente. De este modo, se han introducido los derechos a la propiedad privada, a la instrucción y a la celebración periódica de elecciones libres; a no ser privado de libertad por incumplimiento de obligaciones contractuales, a la libertad de movimiento y residencia en el territorio nacional, la prohibición de ser expulsado del territorio del que se es nacional y la prohibición de deportaciones colectivas de extranjeros; la abolición de la pena de muerte; las garantías que deben observarse en los procedi-

1 La Convención Europea de Derechos Humanos se cita en el texto con la nueva numeración introducida por su Protocolo $n .^{\circ} 11$, que entró en vigor el 1 de noviembre de 1998. 
mientos de expulsión de extranjeros, el derecho a una segunda instancia en materia penal, a compensaciones por errores judiciales, la prohibición de ser juzgado de nuevo por los mismos hechos una vez declarado inocente $y$ la igualdad de derechos entre los cónyuges.

Los derechos protegidos por la CEDH no son derechos absolutos. La propia Convención prevé la posibilidad de limitarlos, tanto en situaciones de emergencia como en circunstancias ordinarias. La mayoría de los artículos de la CEDH, al tiempo que reconocen los derechos, enumeran los requisitos necesarios para limitarlos. Estos requisitos forman el denominado "test de Estrasburgo", es decir, el conjunto de criterios empleados por el TEDH para decidir si una restricción a un derecho reconocido por la Convención supone o no una violación del mismo. El test consta (junto con las particularidades propias de cada derecho) de tres requisitos: la restricción ha de estar predeterminada o prevista por la ley del estado que la impone; ha de estar encaminada a la protección de alguno de los bienes jurídicos que se enumeran en cada caso y ha de ser "necesaria en una sociedad democrática». Este último requisito se ha convertido en el más importante en la jurisprudencia del TEDH, que lo ha usado de modo similar (y a veces conjuntamente) a los criterios de razonabilidad y proporcionalidad aplicados por otras jurisdicciones (como el TC español).

La CEDH, una vez ratificada por España, produce en nuestro ordenamiento efectos jurídicos de dos tipos: de orden internacional y de orden interno. Desde el punto de vista jurídico internacional, España puede ser demandada ante el TEDH por vulneración de algunos de los derechos contenidos en la CEDH o en los protocolos a la misma que haya ratificado. Ahora bien, es preciso destacar que, desde el punto de vista jurídico internacional, las sentencias del TEDH tienen sólo un efecto declarativo de responsabilidad internacional del Estado español, aunque éstas puedan llevar consigo, a tenor de lo establecido en el art. $41 \mathrm{CEDH}$, la fijación de un compensación como justa indemnización para quien haya sido víctima de una violación de sus derechos. Por otra parte, las sentencias del TEDH también tienen efectos internos en nuestro país: el más claro, tempranamente establecido por el TC (desde la STC 5/1981) al aplicar el art. 10.2 CE, es el valor que tiene su doctrina jurisprudencial, que pasa a integrar los criterios para interpretar las normas internas sobre derechos fundamentales. Sin embargo, queda aún sin resolver el efecto interno que debe tener el fallo de una STEDH contra España sobre el propio caso sobre el que se pronuncian, y sobre el que generalmente ya ha existido una sentencia interna en la que no se ha apreciado vulneración de derechos fundamentales. Según el TC, 
el carácter declarativo, en el plano internacional, de las sentencias del TEDH, «no implica la carencia de todo efecto interno de la declaración realizada por dicho Tribunal sobre la existencia de infracción de un derecho reconocido en el Convenio" ( STC 245/1991 fj 2. ${ }^{\circ}$ ), ya que "declarada por Sentencia de dicho Tribunal una violación de un derecho reconocido por el Convenio Europeo que constituya asimismo la violación actual de un derecho fundamental consagrado en nuestra Constitución, corresponde enjuiciarla a este Tribunal, como Juez supremo de la Constitución y de los derechos fundamentales" (fj 3.\%).

\section{B) El Derecho comunitario europeo ${ }^{2}$}

Tras las sucesivas reformas llevadas a cabo por el Tratado de Maastricht (1992) y el Tratado de Amsterdam (1998), las normas de derecho comunitario europeo sobre derechos fundamentales pueden clasificarse del siguiente modo:

En primer lugar, las denominadas tradicionalmente ulibertades comunitarias». Se trata en realidad de una serie de normas dispersas a lo largo de los tratados fundacionales que consagran determinadas políticas comunitarias cuya consecución puede implicar el respeto y la promoción de algunos derechos fundamentales. Así, entre las libertades comunitarias se encontrarían la libre circulación de trabajadores (art. 39 TCE), la libertad de establecimiento (art. 43 TCE) y los derechos individuales que se deducen de principios como la libre circulación de bienes (art. 23 TCE), servicios (art. 49 TCE) y capitales (art. 56 TCE). Estas libertades son, en realidad, políticas comunitarias. A veces pueden implicar la protección de derechos fundamentales, como, por ejemplo, cuando, en virtud de la libre circulación de trabajadores se aprueban directivas sobre la no discriminación en el trabajo por razón de sexo (Directiva 76/207/CEE). Sí debe considerarse como auténtico derecho fundamental comunitario, sin embargo, la prohibición de discriminación por razón de la nacionalidad (art. 12 TCE), si bien esta prohibición se subordina, como todas las normas comunitarias, a su aplicación a situaciones cuya regulación sea competencia de la Unión, lo que, como veremos a continuación, no es fácil de precisar. Ahora bien, las denominadas "libertades comunitarias" no pueden suplir la

2 Tanto el Tratado de la Comunidad Europea (TCE) como el Tratado de la Unión Europea (TUE) se citan en el texto con la nueva numeración que ha introducido el Tratado de Amsterdam. 
ausencia de una declaración de derechos por varias razones. En primer lugar porque no cubren todos los derechos fundamentales que generalmente se incluyen en una declaración sistematizada. En segundo lugar porque las normas que las regulan aparecen en los tratados más como el resultado de determinados principios de política comunitaria que como derechos fundamentales cuyo respeto se considere una exigencia jurídica per se: no se encuentran en el TCE como tales derechos, sino como políticas que debe seguir la Unión, con independencia de que, para su consecución se protejan o se limiten derechos fundamentales.

En todo caso, los derechos que se desprenden de estas normas vinculan, por una parte, a la Unión cuando actúa directamente, bien aprobando normas de derecho comunitario derivado bien mediante una acción administrativa directa; $y$, por otra, a los Estados miembros, siempre que estén implementando legislativamente una política comunitaria (por ejemplo, aprobando una norma de desarrollo de una directiva) o cuando apliquen directamente normas comunitarias. A todo ello debe añadirșe que no existe en derecho comunitario un procedimiento específico de defensa de los derechos fundamentales, cuya protección debe buscarse, en todo caso, siguiendo los cauces procesales ordinarios de este ordenamiento.

Para paliar algunas de estas deficiencias, el TCE cuenta, desde la reforma llevada a cabo por el Tratado de Maastricht, completada posteriormente por el Tratado de Amsterdam, con un apartado dedicado expresamente al establecimiento de una ciudadanía de la Unión y al reconocimiento de los derechos fundamentales que protegen a todos los ciudadanos comunitarios. A diferencia de las libertades comunitarias clásicas, nos encontramos aquí con un catálogo de auténticos derechos subjetivos, de los que son titulares los ciudadanos comunitarios. El catálogo de derechos reconocido es, sin embargo, peculiar: se protegen sólo unos pocos derechos y no todos los de mayor importancia. Así, se reconocen los derechos a residir y circular libremente por el territorio de los Estados miembros (art. $18 \mathrm{TCE}$ ); al sufragio activo y pasivo en el Estado de residencia tanto en las elecciones municipales (art. 19.1 TCE) como en las elecciones al Parlamento Europeo (art. 19.2 TCE); el derecho a la protección consular y diplomática por parte de otro Estado de la Unión de quien se encuentre en un tercer estado en el que el suyo propio no tiene representación (art. 20 TCE); y los derechos de petición ante el Parlamento Europeo, de queja ante el Ombudsman que el propio tratado establece en su art. 195 y de comunicación con las instituciones comunitarias en la lengua oficial de su 
elección (art. 21 TCE). Todos estos derechos se reconocen en el tratado sujetos a las limitaciones que en cada caso el propio tratado establece.

Por último, el art. 6 del Tratado de la Unión contiene, en su apartado primero, una mención explícita al respeto de los derechos humanos y libertades fundamentales como uno de los principios en los que se basa la Unión (junto con los de libertad, democracia y estado de derecho). En su apartado segundo, se especifica que la Unión respetará estos derechos como principios generales del derecho comunitario, tal como se encuentran garantizados por la CEDH y tal como resulta de las tradiciones constitucionales comunes de los estados miembros, dando así forma legislativa a la práctica jurisprudencial del TJCE, previéndose incluso (art. 7 TCE) mecanismos para sancionar aquellos Estados miembros que de forma continua y grave violen en su territorio los derechos humanos. La mención en el TUE de la CEDH no supone sin embargo que ésta se configure como una fuente directa de derecho comunitario, del mismo modo que no lo es el derecho constitucional de los Estados miembros. Del art. 6 TUE sólo puede deducirse que los derechos recogidos en la CEDH y los que se desprenden de las tradiciones constitucionales comunes deben ser respetados por la Unión. Pero el modo en el que este respeto se llevará a cabo, definiendo por tanto la medida en la cual estos derechos pueden ser limitados por normas comunitarias, se controla (en virtud del art. 46 TUE) por el TJCE, que empleará para ello criterios y categorías que deducirá del propio ordenamiento comunitario y no de ningún otro. Cuestión distinta hubiera sido que la Unión, como tal, ratificara como una parte más la propia CEDH, posibilidad que se planteó como una solución plausible al problema de la protección en la comunidad de los derechos fundamentales hasta que el propio TJCE estableció, a requerimiento del Consejo, que la misma no era compatible con el estado actual del derecho comunitario (Dictamen del TJCE 2/94, de 28 de marzo de 1996).

\section{DERECHO EUROPEO Y MAYOR PROTECCIÓN DE LOS DERECHOS FUNDAMENTALES}

El art. 10.2 CE constitucionaliza una vía innovadora, dentro del panorama de derecho comparado sobre la materia, para la recepción interna de los instrumentos internacionales que protejan derechos fundamentales constitucionalmente reconocidos. Su tenor literal obliga a interpretar según los textos internacionales "las normas relativas a los derechos fundamentales y a las libertades que la Constitución reconoce". EI mandato que contiene esta norma constitucional -una autentica norma 
sobre la interpretación- se dirige a todos los operadores jurídicos, pues debe aplicarse -con las particularidades que veremos a continuación- a todos las normas relativas a los derechos fundamentales constitucionalmente reconocidos. Se refiere, pues, no sólo a las normas constitucionales sobre derechos fundamentales, sino a todo tipo de norma que, con independencia de su naturaleza y rango, pueda afectar a estos derechos. En todo caso, el TC ha incluido las propias normas constitucionales entre las que deben ser interpretadas según este artículo. Esto es lo que permite hablar de la "función constitucional" que cumplen las normas internacionales que penetran en nuestro ordenamiento a través del art. 10.2 CE.

Desde un punto de vista tradicional, la cuestión de cuándo debe el juez español aplicar esas normas a los casos de protección de derechos fundamentales constitucionalmente protegidos, ha recibido hasta ahora una respuesta clara y precisa: siempre, en el caso de la CEDH, pues a ello obligaría la entrada en nuestro ordenamiento de esta norma tanto por la vía del art. 96 como por la vía del art. 10.2 CE. Y, en el caso del derecho comunitario europeo, sólo en los casos en los que exista un «punto de conexión" suficiente como para comunitarizar el caso, es decir, cuando éste se encuentre regulado de algún modo por normas comunitarias, pues a ello obligaría la primacia y efecto directo del derecho comunitario.

Ensayemos ahora un intento de construcción alternativa a esta respuestas tradicionales, en las que el criterio sea el de la mayor protección de los derechos. Este criterio implicaría responder a la cuestión anterior, (cuándo debe el juez español aplicar las normas europeas a casos de protección de los derechos fundamentales) en función de si esas normas europeas dispensan o no una mayor protección que las de nuestro ordenamiento. Podríamos distinguir, así, en principio, cuatro situaciones: en primer lugar, aquéllas en la que la CEDH dispensa un estándar de protección mayor que el ordenamiento interno; en segundo lugar, cuando ese estándar de protección es menor; en tercer lugar, la situación de mayor estándar de protección por el derecho comunitario con respecto al ordenamiento interno $y$, por último, la situación de menor estándar de protección por el derecho comunitario con respecto al ordenamiento interno. Veamos a qué conduce cada una de ellas.

\section{A) Convención Europea de Derechos Humanos y mayor protección de los derechos fundamentales}

Como se ha dicho, la CEDH se concibió por sus redactores comó un instrumento que recogiera "el mínimo común" de protección de los de- 
rechos fundamentales entre los Estados miembros del Consejo de Europa. Sin embargo, en cuanto a su relación con España - $y$ ha ocurrido también con otros Estados miembros-su aplicación ha supuesto en numerosas ocasiones elevar el estándar de protección de los derechos protegidos por la Constitución. Este resultado se dio con especial relevancia en los primeros años tras la aprobación de la CE, cuando la labor de interpretación de las normas constitucionales por parte del TC todavía no se había desarrollado. Puede decirse, en puridad, que entonces nos encontrábamos ante una situación en la que no había aún estándar de protección interno, tan sólo una declaración constitucional de derechos cuyo régimen jurídico aún debía completarse mediante el desarrollo legislativo y la interpretación jurisprudencial, tanto ordinaria como constitucional.

Pertenece a este momento la aplicación por parte del TC de la doctrina del TEDH para interpretar las normas constitucionales sobre el derecho a la educación (STC 5/1981), sobre el derecho a la vida (STC $53 / 1985$ ), sobre el derecho a la no discriminación (STC 22/1981), sobre la objeción de conciencia al servicio militar (STC 15/1982), sobre el derecho de sindicación (STC 53/1982), sobre el concepto constitucional de dilaciones indebidas en los procedimientos judiciales y otras garantías integrantes del derecho a la tutela judicial efectiva (SSTC 24/1981, $10 / 1984,44 / 1985,44 / 1987,74 / 1985$ etc.) , y sobre otros derechos fundamentales constitucionales.

Un ejemplo interesante de esta fase de aplicación de la CEDH en nuestro país lo constituye la STC 145/1988, que declaró inconstitucional el art. 2 de LO 10/1980, de enjuiciamiento oral de los delitos dolosos, menos graves y flagrantes, por infringir el principio de imparcialidad del juez penal, principio que el TC entendió incluido entre las garantías propias del derecho a la tutela judicial gracias a la apertura del art. $24 \mathrm{CE}$, que constitucionaliza el derecho a un juicio justo "con todas las garantías", entre las que por lo tanto se incluiría ésta tal y como había sido formulada por la jurisprudencia del TEDH.

El art. 2 de la LO 10/1980, declarado inconstitucional por esta STC, establecía que:

"serán competentes para el conocimiento y fallo de estas causas "las que enjuicien los delitos precisados en la ley" los jueces de ins. trucción del partido en que el delito de haya cometido. En ningún caso les será de aplicación la causa de recusación prevista en el apartado 12 del art. 54 de la Ley de Enjuiciamiento Criminal."

El mencionado artículo de la LECr posibilitaba precisamente la recusación del juez que hubieran instruido la causa, recusación que de- 
jaría ya de ser posible en el caso de los delitos dolosos, menos graves y flagrantes ahora regulados. El artículo 2 de la LO 10/1980 fue objeto de dos cuestiones de inconstitucionalidad, acumuladas por el TC en esta sentencia, cuyo resultado, bien conocido, fue como se ha dicho la declaración de inconstitucionalidad del artículo impugnado por entenderlo contrario al derecho al juez imparcial incluido en el derecho a un juicio justo "con todas las garantías" del art. $24 \mathrm{CE}$.

Hay varias razones para destacar la importancia de esta decisión del TC en cuanto a la aplicación en España de la doctrina del TEDH: se trataba de la primera vez que el TC resolvía una cuestión de inconstitucionalidad sobre una ley española basada de manera muy fundamental (en la práctica era su único argumento) en la infracción de la Constitución por interpretación de sus preceptos según la CEDH. Además, la propia decisión del TC se basaba también de manera casi exclusiva en la interpretación del art. 6.1 CEDH, y citaba expresamente la doctrina de la STEDH De Cubber de 26 de octubre de 1984 antes de acometer su propia construcción del art. $24 \mathrm{CE}$, reconociendo expresamente la identidad de las conclusiones alcanzadas al interpretar la norma constitucional con las formuladas en su día por el TEDH al interpretar la Convención (fj 5. ${ }^{\circ}$. Por último, el TC era plenamente consciente de los problemas que la aceptación directa de la doctrina del TEDH iba a ocasionar para la organización jurisdiccional del pais, y de la necesidad de que fuera el legislador quien asumiera "la tarea de reformar este procedimiento o sustituirlo por otro, removiendo los riesgos que el procedimiento actual crea tanto para los derechos fundamentales como para la buena marcha y eficaz funcionamiento del proceson (fj $7 .{ }^{\circ}$ ). De modo que puede afirmarse que, a la entrada de la década de los noventa, existía ya una línea consolidada en la jurisprudencia del TC que exigía interpretar tanto las leyes como las propias normas constitucionales sobre derechos fundamentales según la doctrina del TEDH y que abriría la puerta a una declaración de inconstitucionalidad de las normas internas que infringieran esa doctrina.

La aplicación de la CEDH y de los estándares de protección construidos por el TEDH ha tenido en nuestro ordenamiento, casi en todas las ocasiones en que se han dado, un efecto de mayor protección tal como le hemos definido aquí. Con todo, conviene poner de relieve que el art. 10.2 CE no ha sido, hasta ahora, aplicado a todos los principios propios del sistema de la CEDH capaces de elevar el estándar de protección interna de los derechos fundamentales. Por ejemplo, la aplicabilidad interpartes ("dritwirkung"), en el caso de algunos derechos fundamentales, del sistema CEDH o la construcción del concepto de 
"interés legítimo" del art. 162.1.b) CE a efectos de la interposición de un recurso de amparo en función del concepto de "víctima» que el art. $34 \mathrm{CEDH}$ instaura como criterio de legitimación activa para interponer una recurso ante el TEDH.

¿Existe la posibilidad de que la CEDH sea objeto de una aplicación en nuestro ordenamiento contraria al criterio de mayor protección? Es decir, ¿cabe su aplicación por parte del juez español de modo que se reduzca el estándar de protección interno de derechos fundamentales? En principio, la respuesta a este interrogante parece ser negativa, en base tanto a argumentos internacionales como internos. Así, en primer lugar, la propia CEDH parece desterrar esta posibilidad al preceptuar en su art. 53 que:

"Ninguna de las disposiciones del presente Convenio será interpretada en el sentido de limitar o perjudicar aquellos derechos humanos y libertades fundamentales que podrían ser reconocidos conforme a las leyes de cualquier Alta Parte Contratante o en cualquier otro Convenio en el que ésta sea parte.»

En alguna ocasión el art. $53 \mathrm{CEDH}$ ha sido mencionado por la jurisprudencia del TEDH, pero en ningún caso ha sido usado para afirmar que dispensar a un derecho la protección que la Convención asegura constituye sin embargo una violación de la propia Convención si con ello se reduce el estándar de protección interno. Es preciso tener en cuenta que no es función del TEDH interpretar el derecho interno de cada Estado, sólo su compatibilidad con la Convención. Más problemático aún resultaría la aplicación del art. $53 \mathrm{CEDH}$ por los tribunales internos, pues es, por su propia naturaleza, una norma dirigida a los órganos de la Convención y no a los de los Estados Miembros.

Desde el punto de vista interno, la propia lógica del art 10.2 CE parece impedir su aplicación para reducir el estándar de protección interno, por lo que debe descartarse en todos los casos en los que ese estándar sea, de manera clara y precisa, superior al dispensado por la CEDH. Por ejemplo, la Convención exige que las limitaciones de determinados derechos por ella protegidos (a la intimidad, la libertad de pensamiento, conciencia y religión, la libertad de expresión, los derechos de reunión y asociación, entre otros) estén, junto con otros requisitos, "previstos por la ley". Esta exigencia, próxima a nuestra reserva de ley, ha sido sin embargo interpretada por el TEDH de un modo muy flexible, pues ha tenido que armonizar las dos versiones auténticas de la CEDH (la inglesa, que exige que las limitaciones estén "prescribed by law" y la francesa que lo formula como "prévue par la loi») $y$, sobre todo, el 
contexto de pluralismo de culturas jurídicas en el que la CEDH se desenvuelve (tanto en países de common law como de derecho civil continental). El resultado de ello ha sido entender cumplido el requisito de "previsto por la ley" siempre que una determinada restricción a un derecho haya podido ser previsible por un ciudadano con un conocimiento medio del ordenamiento del Estado miembro en cuestión. Esa interpretación es mucho menos estricta que la reserva constitucional de Ley Orgánica para el desarrollo de esos mismos derechos que exige el art. $81 \mathrm{CE}$ : una determinada norma, incluso no escrita, que limite un derecho fundamental constitucional, podría fácilmente superar el requisito formal de "prescrito por la ley" según la CEDH, pero no el de reserva de Ley Orgánica exigible constitucionalmente. En estas circunstancias, es claro que ningún operador jurídico español entendería que el art. 10.2 es aplicable para interpretar que la reserva de $L O$ se cumple simplemente cumpliendo con lo establecido con el estándar de la Convención.

Sin embargo, la situación deja de estar tan clara cuando no se trata de una oposición frontal entre dos estándares, el de la CE y el de la $\mathrm{CEDH}$, sino cuando el estándar de protección interno está aún por construir en algunos de sus puntos y se acude, como una de las fuentes para esa construcción, al estándar de la Convención. En algunas ocasiones esta operación si puede significar una reducción del estándar que sería alcanzable con una interpretación independiente de las normas constitucionales internas.

Tomaremos como ejemplo para ilustrar este punto la STC 62/1982. Los editores de un libro sobre educación sexual dirigido a escolares recurrieron en amparo su prohibición ante el TC. Éste, tomando la doctrina de la STEDH Handyside de 7 de Diciembre de 1976, consideró que la protección de la moral puede ser esgrimida como un límite expreso de la libertad de expresión protegida por el art. $20 \mathrm{CE}$. Sin embargo, la moral aparece como límite a la libertad de expresión en el art. $10 \mathrm{CEDH}$, no en la CE. Es cierto que el art. 20.4 CE establece como límite a la libertad de expresión, entre otros, la protección de la juventud y la infancia, pero este límite legitima, al contrario de lo que ocurre en la CEDH, para restringir, no los mensajes, sino el acceso a ellos de determinadas audiencias. Otro ejemplo, también sobre el art. $20 \mathrm{CE}$, lo constituye la legitimidad constitucional de las restricciones previas a la libertad de expresión. Hasta ahora el TEDH, aún con una importante minoria en contra, ha aceptado como compatibles con el art. $10 \mathrm{CEDH}$ las "prior restraints" (SSTEDH The Observer and The Guardian y The Sunday Times (III), ambas de 26 de Noviembre de 1991). La incorporación interna de esta doctrina por nuestros tribunales, sin 
embargo, podría traer consigo consecuencias próximas a la menor protección, pues también en este punto difieren los estándares internos y convencional: la $\mathrm{CE}$, al contrario de la $\mathrm{CEDH}$, prohíbe taxativamente cualquier tipo de censura previa.

\section{B) Derecho comunitario Europeo y mayor protección de los derechos fundamentales}

En la mayor parte de las ocasiones en que se ha aplicado en España, la CEDH ha tenido un efecto más protector de los derechos fundamentales constitucionales. Sin embargo, la presunción de que su aplicación interna no puede, en determinadas circunstancias, producir otros efectos, es, como acabamos de ver, errónea. Con el derecho comunitario ocurre justamente lo contrario: tradicionalmente ha existido el prejuicio de que las normas comunitarias podrían suponer un peligro para los estándares de protección interna de los derechos fundametales tal y como se garantizan por las respectivas constituciones de los Estados Miembros. En realidad, al igual que ocurre con la CEDH, lo cierto es que su aplicación puede tener como consecuencia, según los casos, tanto un incremento como una reducción del nivel o estándar de protección interna.

Aunque la confrontación del principio de mayor protección con respecto al derecho comunitario es, por lo tanto, similar al que se acaba de realizar con respecto a la CEDH, es preciso destacar algunas diferencias importantes. En primer lugar, el derecho comunitario no se toma como criterio de interpretación de las normas internas, sino que se aplica directamente en nuestro ordenamiento con arreglo a los principios de primacía y efecto directo. En segundo lugar, no todo el derecho comunitario se refiere a derechos fundamentales, aunque es evidente que puede afectarlos. En tercer lugar, el derecho comunitario puede afectar a derechos fundamentales constitucionales sólo en el caso de que esos derechos se ejerzan en un ámbito cuya regulación es competencia de la Unión. Esta última es una diferencia sustancial con respecto al sistema de protección de la CEDH, pues ésta se aplica a todos los casos bajo la jurisdicción de un Estado miembro en el que uno de los derechos protegidos por la Convención pueda verse afectado, con independencia del ámbito en el que el derecho se desenvuelva, siendo por lo tanto irrelevante, a estos efectos, quien ostente la competencia para regularlo.

Es por lo tanto posible que los estándares de protección de un mismo derecho constitucionalmente protegido varíen cuando se ejer- 
cen en un ámbito regulado por el derecho comunitario y cuando se hacen en un ámbito regulado por el derecho interno (por ejemplo, en el caso de los derechos de defensa incluidos en el art. 24 CE, según se ejerzan en un procedimiento ante el TJCE o ante tribunales internos). Además, al igual que en el caso de la $\mathrm{CEDH}$, surge el interrogante de bajo qué circunstancias debe el intérprete interno acudir al estándar comunitario para perfilar el estándar de protección en un ámbito regulado por el derecho interno; por ejemplo, si debe el juez español acudir a la jurisprudencia comunitaria sobre la inviolabilidad del domicilio de personas jurídicas, construida para casos en los que se lleva a cabo una inspección de un establecimiento comercial al amparo de normas comunitarias, para definir el estándar de protección de este mismo derecho cuando la inspección ha sido llevada a cabo al amparo de normas de derecho interno.

La respuesta tradicional a esta cuestión apunta a que debe aplicarse el estándar comunitario cuando estemos en un campo regulado por ese ordenamiento y el interno en el resto de los casos. Ello, sin embargo, no constituye una solución satisfactoria al problema. No por el hecho de que reconozca la existencia simultánea de varios estándares de protección -lo que no es extraño desde un punto de vista federalsino por las dificultades de su aplicación como único criterio a tener en cuenta. No es el menor obstáculo el hecho de que no sea en modo alguno pacífico cuándo una materia es competencia comunitaria y cuándo no. Por ejemplo, la jurisprudencia del TJCE aplica el estándar comunitario para proteger la libertad de expresión cuando se entiende la información como un "servicio", en virtud de la libertad comunitaria para prestar éstos en cualquier estado de la Unión. Pero, en consecuencia, la libre circulación de servicios protegerá la libertad de expresión sólo si se trata de información que se presta a cambio de remuneración (STJE Grogan 159/90, de 4 de octubre de 1991) o tiene un enlace económico directo con otra actividad (STJE GB-INNO-BM $362 / 88$, de 7 de marzo de 1990). En todos los demás casos estaremos ante un caso extramuros del derecho comunitario en el que será de aplicación el estándar nacional.

Hay que tener en cuenta que la aplicación interna de estándares comunitarios a ámbitos regulados por el derecho interno podría, en algunos casos, conducir a su elevación. Por ejemplo, el TJCE ha desarrollado jurisprudencialmente el concepto de udiscriminación indirecta", que hasta ahora ha aplicado a los casos de discriminación por razón de sexo en materia laboral. El concepto comunitario de discriminación indirecta ha sido recientemente recogido en la Directiva 97/80, 
del Consejo, de 15 de diciembre de 1997. Según su art. 2.2 , se entiende que existe discriminación indirecta, a los efectos del principio de igualdad de trato,

"cuando una disposición, criterio o práctica aparentemente neutro afecte a una proporción sustancialmente mayor de miembros de un mismo sexo salvo que dicha disposición criterio o práctica no resulte adecuado y necesario y pueda justificarse con criterios objetivos que no estén relacionados con el sexo.»

Aun antes de que el concepto de discriminación indirecta fuera definido mediante esta directiva, cuando era tan sólo una construcción jurisprudencial, fue aceptado y aplicado por los tribunales españoles para proteger en el ámbito laboral el derecho fundamental a no ser discriminado por razón de sexo del art. 14 CE. En este sentido, la STC 145/1991 entendió que el art. 14 CE protege también contra la discriminación indirecta, entendiendo por tal la que incluye "tratamientos no formalmente discriminatorios de los que derivan, por las diferencias fácticas que tienen lugar entre trabajadores de diverso sexo, consecuencias desiguales perjudiciales por el impacto diferenciado y desfavorable que tratamientos formalmente iguales o tratamientos razonablemente desiguales tienen sobre los trabajadores de uno y otro sexo a causa de la diferencia de sexo" (fj 2). La misma doctrina ha sido aplicada, siempre en casos de discriminación laboral por razón de sexo, en las SSTC $147 / 1995$ y $198 / 1996$.

Queda pues claro, siguiendo con este mismo ejemplo, que el ordenamiento comunitario obliga a aplicar el concepto de discriminación indirecta sólo en el ámbito que se encuentra bajo su competencia, es decir, en el momento presente, y por lo que ahora interesa, en el campo laboral y en los casos en los que se alegue una discriminación por razón de sexo. Sin embargo, ¿podría aplicarse el concepto de discriminación indirecta para construir o elevar el estándar de protección del derecho fundamental a la no discriminación por razón de sexo del art. 14 CE en casos que queden fuera del derecho comunitario? Pensemos por ejemplo en casos en donde no se plantea una cuestión jurídico laboral o, aun dentro del campo laboral, en discriminaciones no basadas en el sexo, sino que tenga su origen en la raza, la edad, la ideología etc. Éste es sin duda un campo abierto para una aplicación más protectora del derecho comunitario a la hora de construir el concepto de no discriminación.

En el otro lado de la balanza, y al igual que ocurría con la CEDH, es preciso advertir que la aplicación de los estándares comunitarios de protección de derechos fundamentales puede conducir, en determina- 
das circunstancias, a reducir el nivel de protección que sería alcanzable con una interpretación independiente de las normas internas.

El mismo ejemplo de la discriminación laboral por razón de sexo puede ahora servir para ilustrar esta posibilidad. EI TJCE decidió recientemente, en la STJCE Grant, 246/96, de 17 de febrero de 1998, que la prohibición comunitaria de la "discriminación por razón de sexo" no incluía la prohibición de un trato discriminatorio basado en la orientación sexual. Tras la aprobación del Tratado de Amsterdam, el art. 13 TCE será reformado para incluir una disposición específica contra la discriminación por orientación sexual, por lo que la doctrina del TJCE sobre este punto puede entenderse claramente no aplicable en el futuro. La cuestión, desde el punto de vista de la mayor protección de los derechos fundamentales que aquí se ha ensayado, es si era necesaria esa reforma para que los jueces españoles exploraran una interpretación más avanzada del art. $14 \mathrm{CE}$, tanto en aquellas materias bajo la competencia del derecho comunitario como en otras que no lo están. Esta misma cuestión, con todo, sigue aún abierta, pues aún admitido en el ordenamiento comunitario el derecho a la no discriminación por orientación sexual, resta aún por ver los perfiles concretos con los que este derecho será delimitado jurisprudencialmente.

\section{CONCLUSIONES}

Tras lo que no ha sido sino un ensayo de exploración jurídica, no es aconsejable terminar con un epígrafe cerrado de conclusiones, no al menos por ahora. No debe verse en ello, sin embargo, mal alguno: quizá sean los cursos de verano, tan frecuentes de un tiempo a esta parte en nuestra universidad, la ocasión más propicia para adelantar propuestas, sugerencias o aún impresiones, del estilo de las que se han enunciado aquí. Debe advertirse, sin embargo, que ello no nos debe hacer eludir la labor que, tras lo dicho, nos aguarda para el invierno: sistematizar lo aquí propuesto para que pueda tomar cuerpo -si lo merece- como una elaboración doctrinal aplicable.

A la espera de que la hipótesis de la mayor protección pueda adquirir esa naturaleza, una nueva metáfora, no, por lo dicho, para concluir, sino para finalizar: se ha descrito con acierto la nueva feudalización a la que, también en el orden jurídico, nos conduce, paradójicamente, el proceso de integración supranacional al que asistimos, no sólo en el orden europeo, sino también en el mundial. En esta nueva realidad jurídica que se nos aproxima, en la que las fronte- 
ras entre los ordenamientos dejarán de parecerse a las fronteras cartográficamente precisas de los Estados modernos para acercarse a las marcas o tierras de nadie medievales, no deja de ser sugerente la idea del juez que se alza, como las órdenes de caballería de entonces, a la búsqueda de la norma, del ordenamiento, que en cada caso pueda mejor proteger los derechos de sus conciudadanos. 